\title{
New evidence for the transcontinental spread of early faience
}

Yingzhu Wang ${ }^{a, b}$, Thilo Rehren ${ }^{c, d}$, Yuchen Tan ${ }^{b}$, Dexin Conge, Peter W. Jia ${ }^{f *}$, Julian Hendersong, ${ }^{\mathrm{h}}$, Hongjiao $\mathrm{Ma}^{\mathrm{b}}$, Alison Betts ${ }^{f}$, Kunlong Chen $^{\mathrm{b} \ddagger}$

a. Department of conservation technology and traditional skills, Capital Museum, Beijing, PR China

b. Institute for Cultural Heritage and History of Science and Technology, University of Science and Technology Beijing, Beijing, PR China

c. UCL Institute of Archaeology, London, UK

d. The Cyprus Institute, Science and Technology in Archaeology and Culture, Nicosia, Cyprus

e. Institute of Archaeology, Chinese Academy of Social Sciences, Beijing, PR China

f. Department of Archaeology and China Studies Centre, Faculty of Arts and Social Science, University of Sydney, NSW 2006, Australia

g. Department of Classics and Archaeology, School of Humanities, University of Nottingham, University Park, Nottingham, NG7 2RD, UK

h. University of Nottingham, 199 Taikang Road, Ningbo, China

Abstract: This paper presents compositional results for six faience beads from Adunqiaolu, an Early Bronze Age site in western Xinjiang, China. It is shown that all analysed samples were made of mixed-alkali flux with sodium oxide $8-10 \%$ and potassium oxide $5-9 \%$. The microstructure of samples indicates that cementation glazing was used. The analytical results, together with the typology of the faience beads were then compared with data of Bronze Age faience beads found in Europe and East Asia. There are clear similarities in both typological and technological features. As the earliest faience objects discovered in China so far, the Adunqiaolu beads set an essential starting point for the further discussion on the early exchange network evidenced by faience products and long distance transmission of technologies and knowledge. This observation is of significance for deepening our understanding of prehistoric exchange between West and East across the Eurasian continent by providing another element in addition to metallurgy, cereal crops and herding animals.

Key words: faience, Xinjiang in China, Adunqiaolu, technology, cultural exchange

\section{Introduction}

\subsection{Definition of faience}

Faience is a silicate material composed of a body of fine quartz particles and an alkali glaze and is usually blue-green in colour because of the presence of copper. The term 'Egyptian faience' is commonly used to refer to this type of faience, which is different from the brightly-coloured medieval opaque white lead-glazed pottery from

\footnotetext{
*Corresponding author: email peter.jia@sydney.edu.au

${ }^{\ddagger}$ Corresponding author: email kunlong.chen@ustb.edu.cn
} 
Southern Europe known as 'faience' or 'faenza' owing to its origins in the Italian city of Faenza. In this paper, 'faience' refers to 'Egyptian faience' and not to the medieval faenza. In antiquity faience was widely produced in many places across the Old World, including Spain, Scotland (Sheridan et al., 2004), Russia (Shortland et al., 2007), Mesopotamia (Bouquillon et al., 2008), India (Bouquillon et al., 2008; Gu et al., 2016) and North Africa (Kaczmarczyk et al., 2008). It was also found across Central China (Li et al., 2009; Lei and Xia, 2015; Dong et al., 2016).

According to Tite et al. (1983) and Vandiver (1983), there are three common methods for producing the glaze, namely cementation, efflorescence and application. The glazing method used can be reflected by studying the microstructure of the object (Tite et al., 1983; Vandiver, 1983). However, Vandiver (1998) noted that these microstructural criteria must be used with caution because microstructural features do not always provide clear evidence for which technique was used. Tite (2007) also points out that macroscopic evidence, such as size and shape, can assist in identifying the glazing method.

One frequently used criterion for distinguishing the different raw materials used in faience production is the oxide weight ratio between soda and potassium oxide in the vitreous phase, using which soda-rich, mixed-alkali and potash-rich faience can be distinguished. Soda-rich faience is often defined as having an alkali ratio of 3 or greater (Vandiver, 2008), whereas the alkali ratios of mixed-alkali and potash-rich faience are not as well-defined. In a recent paper, Lin et al. (2019) tentatively suggested that a ratio of 0.4 should be used to distinguish between mixed-alkali and potash-rich faience; nevertheless, this value is not sufficiently supported by analytical data (Lin et al., 2019). However, this distinction is of relevance because soda-rich faience is thought to have originated in Egypt or in similar western desert areas, whereas mixed-alkali faience (and glass) is commonly found in Europe (Henderson 1993, Henderson 2013, 192). Thus far, potash-rich faience has only been found in China. Therefore, faience is an important indicator of the material and cultural exchange between China and the West that led to the development of a distinct technical tradition in the Chinese heartland.

\subsection{Recent progress of early faience in China}

Sites where faience has been unearthed in China are shown in Figure 1. As welldocumented materials in the Yellow River basin area (location No. 6-16 in Figure 1), most early faience objects date from the era of the Western Zhou Dynasty (1046-771 $\mathrm{BC}$ ). Most of them belonged to the potash-rich type and were probably made locally (Lei and Xia, 2015; Gan, 2016). In contrast, the earliest faience was soda rich. This was unearthed from tomb $\mathrm{M} 113$, dating to the early and middle period of Western Zhou Dynasty, in the Marquis Jin Cemetery of Shan'xi Province (see location No. 11 in Figure 1) (Lei and Xia, 2015). This soda rich faience had a similar composition to that of the faience usually found in the Near East, Egypt and Indus Valley dating from the end of the $5^{\text {th }}$ millennium BC onward (Tite and Shortland, 2008). The western soda-rich faience found in China implies that faience production in China was influenced by western faience making technology (Li et al., 2009; Lei and Xia, 2015; Dong et al., 2016). Xinjiang, which is a geographical part of Central Asia, is located in north-western China and is an important crossroads of the ancient Silk Road from at least the $2^{\text {nd }}$ millennium 
BC. The use of faience in Xinjiang, for instance in Tianshanbeilu (Lin et al., 2019) and in the Ya'er Cemetery (Liu et al., 2017) took place before the use of faience in the Yellow River basin area. There are two contradictory opinions regarding Xinjiang: Lin et al. (2019) proposed that Eastern Xinjiang did not substantially contribute to the faience production in the Jin-Shan region of the Yellow River basin, while Yang argued that Eastern Xinjiang had an important impact on the faience production in Western Zhou Dynasty (Yang Yimin, pers. com.).

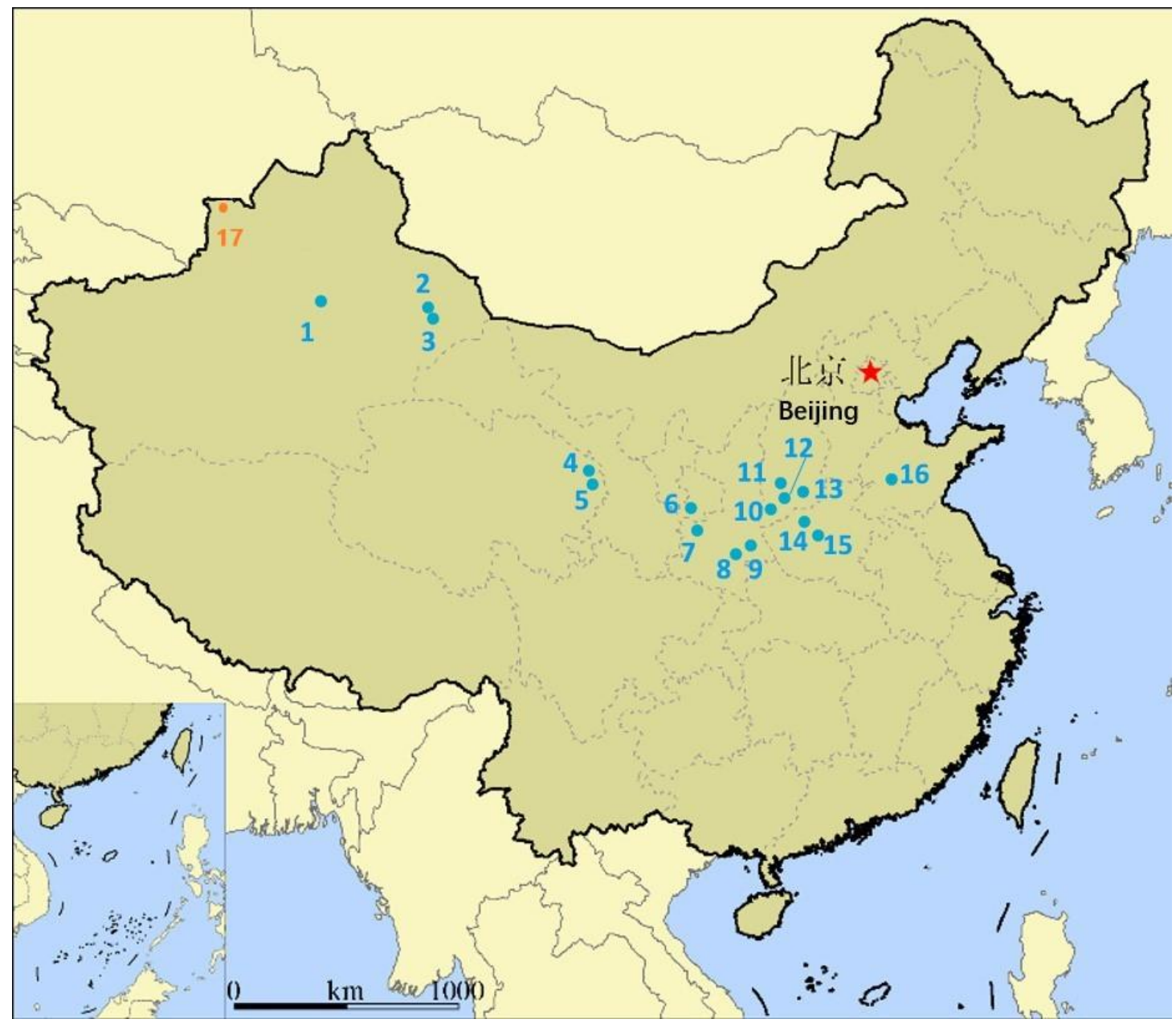

Fig 1. Location of sites with faience in China (c. 1500-771 BC): 1. Saensayi; 2. Tianshanbeilu; 3. Ya'er; 4. Shangsunjiazhai; 5. Banzhuwa; 6. Yujiawan; 7. Yuguo Cemetery; 8. Shaolingyuan Cemetery; 9. Zhangjiapo; 10. Pengguo Cemetery; 11. Tianma-qucun; 12. Yangshe; 13. Dahekou; 14. Luoyang Zhongzhoulu; 15. Yingguo Cemetery; 16. Luguo Cemetery; 17. Adunqiaolu Cemetery.

New excavations at Adunqiaolu in western Xinjiang has provided further information regarding early faience in China and cultural exchange during the early $2^{\text {nd }}$ millennium BC. Forty-seven faience beads were discovered at the Adunqiaolu site (Cong et al., 2013; Cong et al., 2017; Jia et al., 2017). Unlike most faience findings that were scattered along the upper reaches of the Yellow River in China (Gan, 2016), Aduniqiaolu faience is not only located in the westernmost part of China (far from the Yellow River), but is also the earliest faience that has been found in China so far. In this study, compositional analyses are performed using electron microprobe (EPMA) to 
compare Adunqiaolu faience to that discovered in other regions. We also consider research works regarding faience excavated across the broad area located to the west of China. Subsequently, we attempt to discuss the cultural interactions reflected in faience trade and production within these regions.

\section{Materials and archaeological context}

The Adunqiaolu site is located in the upper region of the Boertala Valley in the Wenquan County of Xinjiang in China. The site is situated on an open slope below the foothills of the Alatao, which is one of the western ranges of the Tianshan Mountains (Figure 1, location no. 17). It dates from the $19^{\text {th }}$ to $15^{\text {th }}$ century BC (Jia et al., 2017). The Adunqiaolu site is considered a local Bronze Age assemblage strongly influenced by the Andronovo Complex of the Eurasian Steppe. The Adunqiaolu Cemetery is located at the southern part of the site, with more than 60 tombs found so far. Some segmented faience beads were found in tomb SM41. As excavation work and the documentation of archaeological materials unearthed from Adunqiaolu tombs are still in progress, it is hard to determine whether there is faience in other tombs or not. According to the published reports for tombs SM4 and SM50, no faience products have been found (Cong et al., 2013).

The forty-seven faience beads were excavated from a stone cist in a single tomb within a stone slab enclosure (No. SM41). A burnt bone found in SM41 was sent for radiocarbon dating at Institute of Earth Environment, CAS (Lab code: XA-17133). The conventional radiocarbon date of tomb SM41 is $3330 \pm 30 \mathrm{BP}$ and the calibrated date with $2 \sigma$ confidence interval $(95.4 \%)$ is between 1689-1528 BC (Cong, 2017). All the beads have rounded profiles, are segmented and are undecorated. The number of segments varies from two to eight. Some of the beads were found broken into pieces. The beads have a blue-green colour, and some are opaque white owing to partial weathering. The length of the six samples range from $2.9 \mathrm{~mm}$ to $9.2 \mathrm{~mm}$, with diameters ranging from $2.0 \mathrm{~mm}$ to $2.3 \mathrm{~mm}$. The wall thickness of the faience cross sections ranges from $0.11 \mathrm{~mm}$ to $0.37 \mathrm{~mm}$ (Fig. 2).

Six beads, including the one on the top right and three at the bottom row in Figure 2 as well as another two broken pieces (not shown), chosen from the forty-seven beads, were selected for analysis. They were cut to produce the studied samples and labelled as ADQL001, ADQL002, ADQL003, ADQL004, ADQL005 and ADQL006.
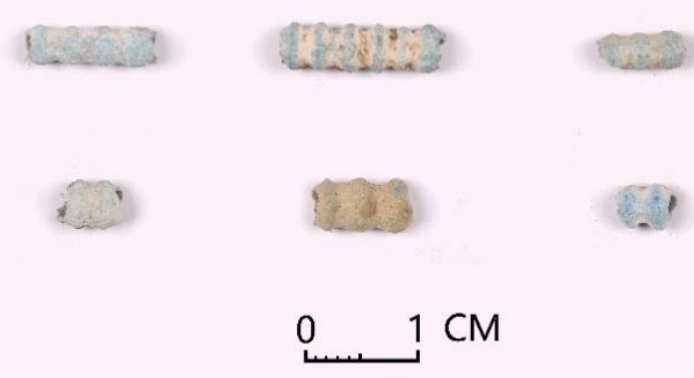


\section{Methods and results}

Cross sections of the samples were obtained by cutting six segmented faience beads and embedding them into polyester resin. Subsequently, the cross sections were exposed and polished to obtain a flat surface and carbon-coated prior to analysis by scanning electron microscopy (SEM) and electron probe micro-analysis (EPMA). A Hitachi S-3600N SEM was used to observe their microstructure in backscatter electron (BSE) images at the Laboratory of Archaeometry at the USTB Institute of Cultural Heritage and History of Science and Technology. The chemical composition of the inter-particle vitreous phase were determined using a SHIMADZU EPMA-1720H EPMA at the State Key Laboratory of Advanced Metallurgy, USTB. Quantitative chemical analyses were conducted at an accelerating voltage of $15 \mathrm{kV}$ and a $20 \mu \mathrm{A}$ beam current. A focused $5 \mu \mathrm{m}$ beam was used so as to avoid the analysis (at least horizontally) of the quartz particles near the glass. The standard (Corning Museum glass B) was analysed three times. The results of the tests for the Corning glass B standard obtained using the EPMA are presented in the last four lines in Table 1.

The BSE images of the cross sections (Figure 3) show that these faience beads were mainly composed of quartz particles with more or less inter-particle glass (IPG). No quartz-free glaze layers (GLZ) were observed and only interaction layers (IAL) were found. The thickness of the cross sections ranged from $500 \mu \mathrm{m}$ to $2000 \mu \mathrm{m}$. The different layers that are easily distinguishable can be observed from the images of ADQL001 (Figure 3a), ADQL002, ADQL004 and ADQL006. The microstructure of the layers rich in IPG was denser, while those of the body layers were more porous. Sample ADQL003 was unique because it consisted of two layers: the first one was entirely homogeneous with quartz particles and interparticle glass. The second one only had sintered particles without any interparticle glass (Figure $3 \mathrm{~b}$ ). There was a round bubble near the bottom of the second layer which was similar to those present in the first layer. This indicates that the second layer suffered serious corrosion (leading to the serious depletion of alkalis) and that this layer was part of sample ADQL003 rather than adhering soil from the burial environment. The boundary between the body and the IPG-rich layers of sample ADQL005 was difficult to recognise (Figure 3c). Variable amounts of interparticle glass were observed in the body when enlarged to $100 x$ (Figure 3d). 


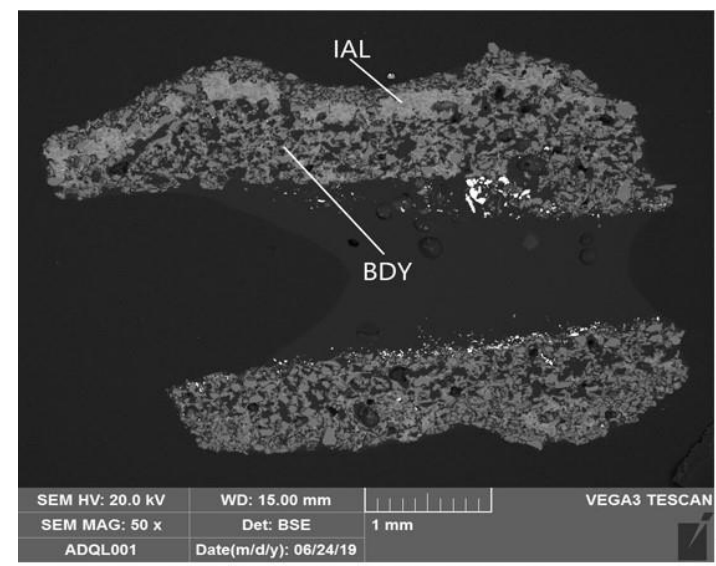

(a) ADQL001 (50x)

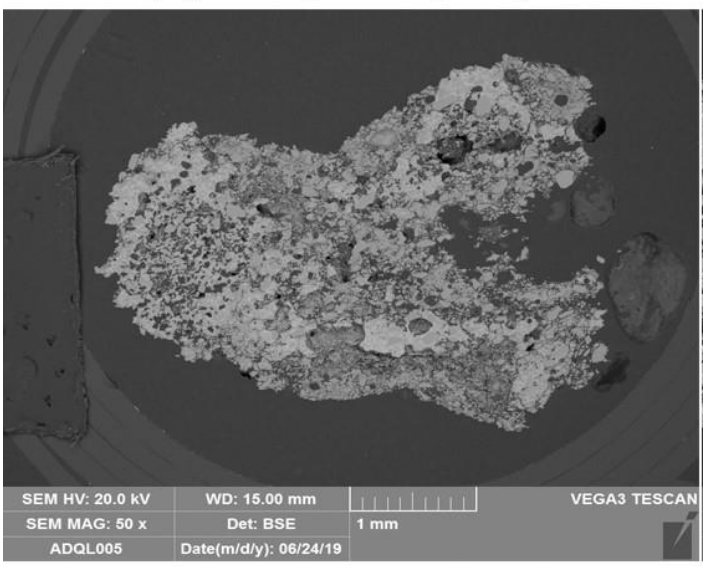

(c) ADQL005 (50x)

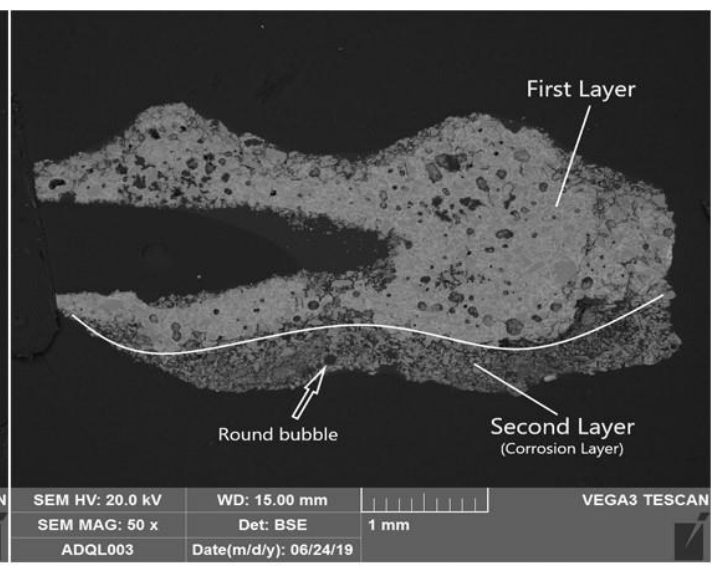

(b) ADQL003 (50x)

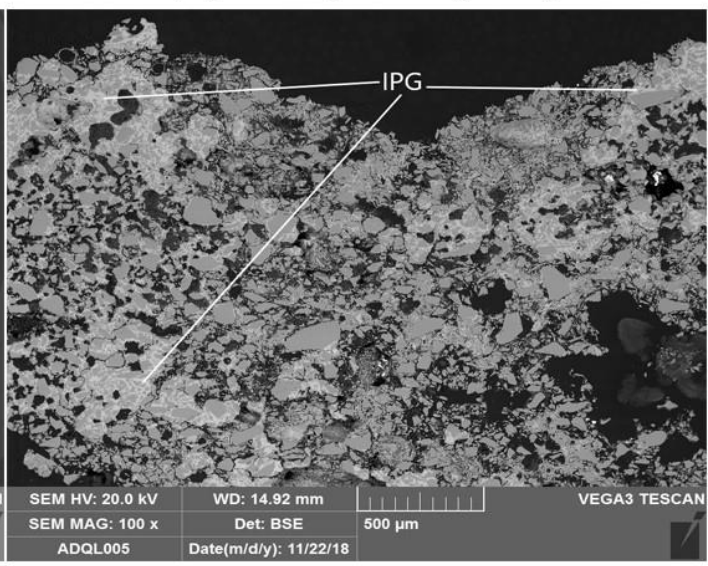

(d) ADQL005 (100x)

Fig. 3 BSE images of cross-section of Adunqiaolu samples

The interparticle glass (IPG) present in the interaction layer (IAL) and in the body (BDY) was analysed at three different areas from each (Table 1). The six samples were distinctively high in $\mathrm{Na}_{2} \mathrm{O}$, with mean concentrations ranging from 8-10 wt\% while the $\mathrm{K}_{2} \mathrm{O}$ concentrations ranged from 5-9 wt\%. Soda concentrations were equal to or greater than that of potash, with $\mathrm{Na}_{2} \mathrm{O} / \mathrm{K}_{2} \mathrm{O}$ ratios from 0.8 to 2.1 . Regarding the main impurities found, the mean concentration of $\mathrm{CaO}$ was approximately $1.7 \mathrm{wt} \%$ and the mean concentration of $\mathrm{MgO}$ was $0.4 \mathrm{wt} \%$. The six samples contained less than $0.4 \mathrm{wt} \%$ $\mathrm{P}_{2} \mathrm{O}_{5}$. The concentrations of $\mathrm{SnO}_{2}$ and $\mathrm{PbO}$ in the six samples was found to be less than 0.3 wt\%. Copper was found to be the colourant used, with concentrations of $\mathrm{CuO}$ ranging between 5 and 10 wt\%.

Table 1. Average compositions for the six faience beads

\begin{tabular}{|c|c|c|c|c|c|c|c|c|c|c|c|c|c|c|c|c|}
\hline $\begin{array}{c}\text { Sample } \\
\text { no. }\end{array}$ & Test area & $\mathrm{Na}_{2} \mathrm{O}$ & $\mathrm{K}_{2} \mathrm{O}$ & $\mathrm{TiO}_{2}$ & MgO & $\mathrm{SiO}_{2}$ & $\mathrm{Fe}_{2} \mathrm{O}_{3}$ & $\mathrm{Al}_{2} \mathrm{O}_{3}$ & $\mathrm{Cl}$ & CuO & $\mathrm{CaO}$ & $\mathrm{SnO}_{2}$ & $\mathrm{PbO}$ & $\mathrm{P}_{2} \mathrm{O}_{5}$ & $\mathrm{Na}_{2} \mathrm{O} / \mathrm{K}_{2} \mathrm{O}$ & $\begin{array}{c}\text { Unnormalized } \\
\text { total }\end{array}$ \\
\hline \multirow[t]{2}{*}{ ADQL001 } & IAL-mean & 9.06 & 7.00 & NA & 0.50 & 67.9 & 0.59 & 1.59 & 1.28 & 9.90 & 1.93 & NA & NA & 0.20 & 1.30 & 100.57 \\
\hline & BDY-mean & 8.14 & 8.41 & 0.10 & 0.53 & 67.3 & 0.72 & 1.80 & 1.24 & 8.86 & 2.30 & 0.31 & NA & 0.27 & 1.00 & 99.75 \\
\hline \multirow[t]{2}{*}{ ADQL002 } & IAL-mean & 7.52 & 9.37 & 0.11 & 0.18 & 70.4 & 1.16 & 1.82 & 0.88 & 7.81 & 0.55 & NA & NA & 0.15 & 0.80 & 98.43 \\
\hline & BDY-mean & 7.53 & 9.32 & NA & 0.56 & 72.0 & 0.52 & 2.37 & 0.81 & 5.17 & 1.45 & NA & NA & 0.20 & 0.80 & 97.18 \\
\hline ADQL003 & IAL-mean & 8.92 & 6.68 & NA & 0.23 & 70.5 & 0.37 & 2.09 & 1.02 & 8.95 & 0.83 & NA & NA & 0.29 & 1.30 & 98.15 \\
\hline
\end{tabular}




\begin{tabular}{|c|c|c|c|c|c|c|c|c|c|c|c|c|c|c|c|c|}
\hline $\begin{array}{c}\text { Sample } \\
\text { no. }\end{array}$ & Test area & $\mathrm{Na}_{2} \mathrm{O}$ & $\mathrm{K}_{2} \mathrm{O}$ & $\mathrm{TiO}_{2}$ & MgO & $\mathrm{SiO}_{2}$ & $\mathrm{Fe}_{2} \mathrm{O}_{3}$ & $\mathrm{Al}_{2} \mathrm{O}_{3}$ & $\mathrm{Cl}$ & CuO & $\mathrm{CaO}$ & $\mathrm{SnO}_{2}$ & Pbo & $\mathrm{P}_{2} \mathrm{O}_{5}$ & $\mathrm{Na}_{2} \mathrm{O} / \mathrm{K}_{2} \mathrm{O}$ & $\begin{array}{c}\text { Unnormalized } \\
\text { total }\end{array}$ \\
\hline & BDY-mean & 9.00 & 6.47 & NA & 0.22 & 71.8 & 0.38 & 2.04 & 0.41 & 8.42 & 0.84 & NA & NA & 0.38 & 1.40 & 97.58 \\
\hline \multirow[t]{2}{*}{ ADQL004 } & IAL-mean & 9.76 & 4.76 & NA & 0.62 & 69.8 & 0.60 & 1.81 & 1.30 & 6.70 & 4.28 & NA & NA & 0.23 & 2.10 & 99.79 \\
\hline & BDY-mean & 8.66 & 4.66 & NA & 0.57 & 73.3 & 0.71 & 2.66 & 1.24 & 4.75 & 3.13 & NA & NA & 0.21 & 1.90 & 99.03 \\
\hline \multirow[t]{2}{*}{ ADQL005 } & IAL-mean & 7.75 & 8.61 & 0.30 & 0.27 & 70.5 & 1.76 & 1.88 & 0.91 & 7.27 & 0.59 & NA & NA & 0.19 & 0.90 & 99.78 \\
\hline & BDY-mean & 8.64 & 8.60 & NA & 0.29 & 70.3 & 0.38 & 2.52 & 1.00 & 7.28 & 0.66 & NA & NA & 0.22 & 1.00 & 98.28 \\
\hline \multirow[t]{2}{*}{ ADQL006 } & IAL-mean & 9.14 & 6.30 & NA & 0.42 & 70.0 & 0.67 & 1.74 & 1.29 & 8.03 & 2.13 & NA & NA & 0.25 & 1.50 & 98.93 \\
\hline & BDY-mean & 8.04 & 8.51 & 0.10 & 0.64 & 68.2 & 1.47 & 2.41 & 1.05 & 7.44 & 1.83 & NA & NA & 0.27 & 0.90 & 97.31 \\
\hline \multicolumn{2}{|c|}{ Corning glass B } & $\mathrm{Na}_{2} \mathrm{O}$ & $\mathrm{K}_{2} \mathrm{O}$ & $\mathrm{TiO}_{2}$ & MgO & $\mathrm{SiO}_{2}$ & $\mathrm{Fe}_{2} \mathrm{O}_{3}$ & $\mathrm{Al}_{2} \mathrm{O}_{3}$ & $\mathrm{Cl}$ & CuO & $\mathrm{CaO}$ & $\mathrm{SnO}_{2}$ & Pbo & $\mathrm{P}_{2} \mathrm{O}_{5}$ & & Sum \\
\hline \multicolumn{2}{|c|}{ Test-1 } & 16.41 & 1.04 & 0.14 & 1.06 & 61.3 & 0.32 & 4.18 & 0.18 & 3.03 & 8.82 & NA & NA & NA & & 96.51 \\
\hline \multicolumn{2}{|c|}{ Test-2 } & 16.48 & 0.98 & 0.11 & 1.07 & 59.9 & 0.32 & 4.19 & 0.17 & 2.98 & 8.66 & NA & NA & 0.87 & & 95.71 \\
\hline \multicolumn{2}{|c|}{ Test-3 } & 16.03 & 0.99 & 0.12 & 1.06 & 61.2 & 0.33 & 4.27 & 0.20 & 3.04 & 8.75 & NA & 0.48 & 0.85 & & 97.36 \\
\hline \multicolumn{2}{|c|}{ Reference content wt\% } & 17.00 & 1.00 & 0.09 & 1.03 & 61.6 & 0.34 & 4.36 & 0.20 & 2.66 & 8.56 & 0.04 & 0.61 & 0.82 & & 97.36 \\
\hline
\end{tabular}

Composition profiles of ADQL001, ADQL002, ADQL004 and ADQL006 indicate a decrease in the levels of soda from the interaction layer to the interparticle glass in the body, whereas an increase was observed in samples ADQL003 and ADQL005 (Figure 4a). A decrease in the copper oxide content was observed in all the samples except for sample ADQL005 (Figure 4b).

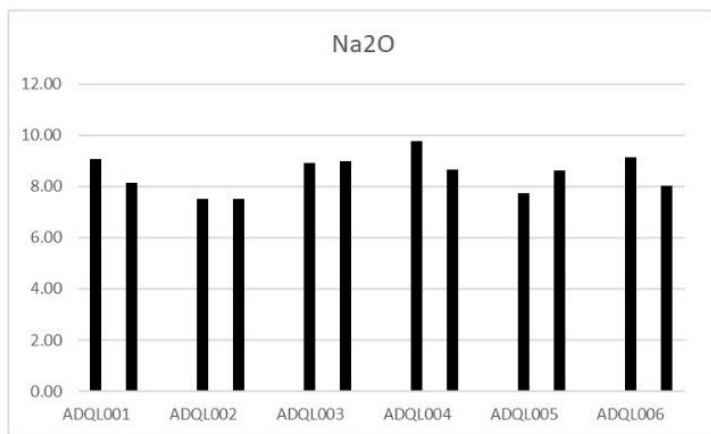

(a) soda concentration

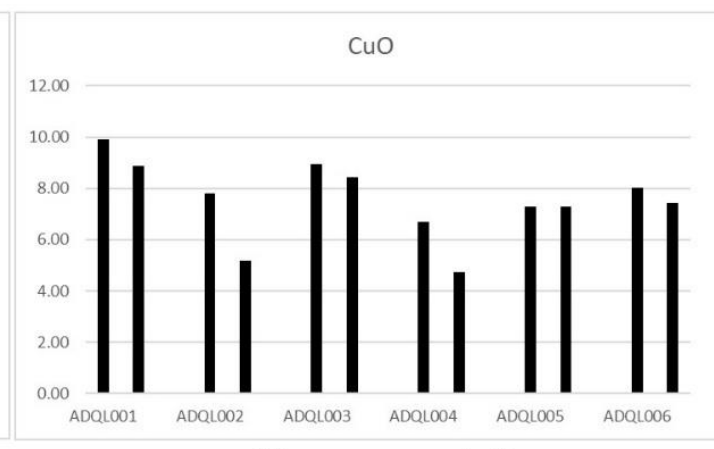

(b) copper concentration

Fig.4 Soda and copper oxide concentration profiles from iteraction layer glass phase (IAL) to the body interparticle glass (BDY)

\section{Discussion}

\subsection{Glazing method}

Based on the soda concentration profile and the microstructure of the six samples, Adunqiaolu faience can be divided into two groups. The first group consists of samples ADQL001, ADQL002, ADQL004, and ADQL006. In these samples, quartz particles are loosely bonded in a very porous body with little glassy content. The interaction layers of these samples are better fused and can be clearly identified from BSE. The existence of a clear boundary between the interaction layer and the body suggests that these four samples were made using the cementation technique or the application glazing method. Although the bodies were porous, inter-particle glass was still present. Vandiver (2008) proposed that some flux/fluxes might have been used as raw materials for improving the plasticity of the body during the forming process. This 
could explain the occurrence of a limited IPG phase in the body. Cementation glazing method has the advantage of glazing a large number of small objects at the same time (Tite et al., 2007). Therefore, these four beads were probably made by cementation glazing. This is consistent with the decrease in the soda content from the interaction layer vitreous phase to the body interparticle glass in samples ADQL001, ADQL002, ADQL004 and ADQL006, as suggested by Tite et al. (2007).

In the second group, the cross section of samples ADQL003 and ADQL005 showed a homogeneous structure with no clear boundaries between the outer layer and the body. In ADQL003, a continuous glass phase has formed in which the whole cross section consisted of quartz particles in a continuous matrix. This type of faience structure has also been observed in faience artefacts from the Yu State cemeteries in Shaan'xi Province, the Peng State cemeteries in Shan'xi Province, and in Rui State cemeteries in Shaanxi Province (Lei and Xia, 2015). Faience with this type of structure was probably produced by employing an efflorescence glazing method (Tite et al., 2007). Although the increase in the presence of soda from the interaction layer glass phase to the body interparticle glass in samples ADQL003 and ADQL005 also indicates that they were made by efflorescence glazing technique, the cementation method cannot be ruled out completely. Matin et al. (2016) observed that extensive interparticle glass in the body can form during the cementation method if the body is thin. Furthermore, the decrease of copper oxide from the interaction layer into the body in sample ADQL003 is a likely indicator of the cementation, too (Tite et al., 2007).

\subsection{Fluxes and colorants}

The main fluxing agents found in Adunqiaolu faience are sodium oxide (8-10 wt\%) and potassium oxide (5-9 wt\%), with low contents of magnesium oxide (average concentration less than $0.5 \mathrm{wt} \%$ ), lime (average concentration less than $2 \mathrm{wt} \%$ ) and phosphorus oxide (average concentration less than $0.3 \mathrm{wt} \%$ ). The composition of Adunqiaolu faience glass phase is similar to that of the Late Bronze Age low magnesium high potassium (LMHK) mixed-alkali glass found in Southern Europe, such as in Greece (Nikita and Henderson 2006; Nikita et al., 2017), Northern and Southern Italy (Angelini et al., 2004; Conte et al., 2019), France (Gratuze, 1998) and even in Ireland (Henderson, 1988; Henderson, 2013, 192-196). This type of glass has high contents of soda and potash, and low contents of calcium, magnesium and phosphorus (Henderson, 1988).

The six samples contain $\mathrm{CuO}$ at a level between 5-10 wt\% which indicates that they were coloured by copper. The concentrations of tin and lead were less than 0.1 $w t \%$. Therefore, it is unlikely that tin bronze or leaded bronze were the sources of the colorant.

As stated earlier, in Central China, faience first appeared during the Western Zhou Dynasty (about 1000 BC) and is characterised by a potash-rich flux (Brill et al., 1989; Dong et al., 2016). Some of these potash-rich faience beads are of the mixed-alkali type and have been found in Shaan'xi and Shan'xi Provinces in Central China. In contrast to Adunqiaolu faience, these mixed-alkali faience beads in Central China contain more potassium oxide (6-11 wt\%) than sodium oxide (4-7 wt\%) as reported by Lei and Xia (2015) and Wang (2019). Moreover, segmented-shaped beads similar to the Adunqiaolu faience have not been found in Central China yet. Although the Central 
Chinese faience production might have been influenced by the West (Li et al., 2009; Lei and Xia, 2015; Wang, 2019), it is not possible to establish a connection between Adunqiaolu faience and the mixed-alkali faience in Central China yet because of the great distance and the differences in chronologies.

In contrast to the faience found in Central China, Adunqiaolu faience is more likely to be linked to European faience. In fact, LMHK mixed-alkali faience like Adunqiaolu faience is mainly distributed in Europe, including Russia (Shortland et al., 2007), Slovakia (Angelini et al., 2006), Poland (Robinson et al., 2004), Britain (Sheridan et al., 2005), Italy (Santopadre et al., 2000; Angelini et al., 2005; Angelini et al., 2006) dating from $2300 \mathrm{BC}$ to $900 \mathrm{BC}$. The date of our faience, 1661-1546 BC, falls into this period. Figure 5 shows that six samples of Adunqiaolu faience group together with other published European mixed-alkali faience samples in the plot of $\mathrm{Na}_{2} \mathrm{O}+\mathrm{K}_{2} \mathrm{O}$ against $\mathrm{Na}_{2} \mathrm{O}$.

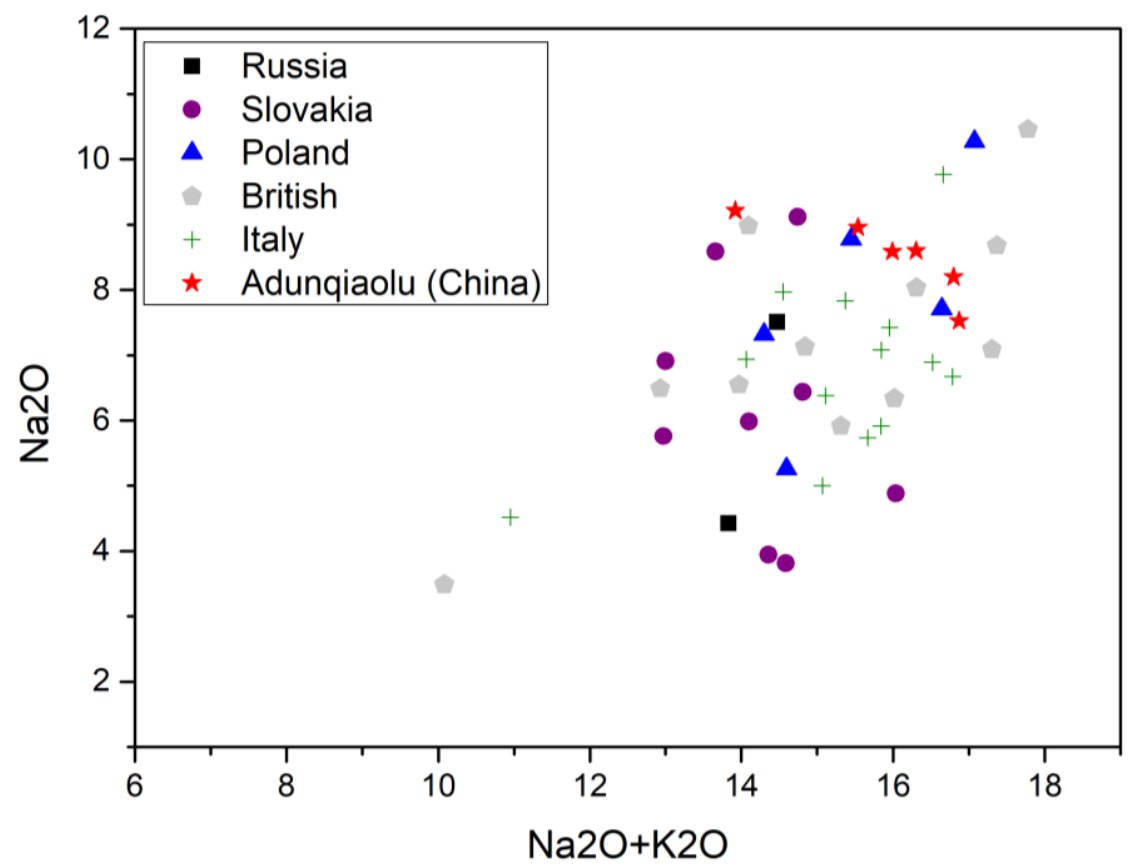

\section{Fig 5. Scatter plot showing the concentrations of $\mathrm{K}_{2} \mathrm{O}$ and $\mathrm{Na}_{2} \mathrm{O}$ of European and} Adunqiaolu faience (wt\%)

According to the composition cited above, the total alkali content $\left(\mathrm{Na}_{2} \mathrm{O}+\mathrm{K}_{2} \mathrm{O}\right)$ of European mixed-alkali faience is fairly consistent (10-18 wt\%) and $\mathrm{Na}_{2} \mathrm{O}$ is commonly at a level of $4-11$ wt\% for most of the samples. Similarly, the total alkali content of Adunqiaolu faience (12-19 wt\%) is overlap the range of European mixed-alkali faience. Furthermore, their $\mathrm{Na}_{2} \mathrm{O}$ content (8-10 wt\%) cluster in the upper part of the European mixed-alkali faience compositional range. The relatively low concentrations of lime (1$4 \mathrm{wt} \%$ ) and magnesia ( $<1 \mathrm{wt} \%$ ) are another common feature of mixed-alkali faience as well as of glass (Henderson, 1988; Santopadre et al., 2000). Based on the literature cited above, the concentrations of lime (0.4-4.9 wt\%, average: $2.3 \mathrm{wt} \%$ ) and magnesia (0.2-3.4 wt\%, average: $0.9 \mathrm{wt} \%)$ of European mixed-alkali faience are very low, and the contents of lime (0.6-4.0 wt\%, average: $1.7 \mathrm{wt} \%)$ and magnesia (0.2-0.6 wt\%, average: $0.4 \mathrm{wt} \%)$ of Adunqiaolu faience fall well within these ranges of mixed-alkali faience. Overall, the concentrations of major and minor constituents in European and 
Adunqiaolu faience are very similar. In addition to the similarity of compositions, the shape of the Adunqiaolu faience beads is also similar to that of European faience beads (as discussed below).

In the glass phase of our six samples, the concentration of soda and potash are negatively correlated (Figure 6). A similar trend was also observed in mixed-alkali glass in Bohemia, west of present-day Czech Republic (Venclová et al., 2011) and also in mixed-alkali glasses from Italy, Switzerland, France, Germany, Greece and Ireland (Henderson 2013, Fig. 6.17). The negative correlation between soda concentration and potash concentration is caused by the relatively constant sum of alkali oxides necessary to produce silica glass at a specific temperature, as shown experimentally (Rehren, 2000; Shugar and Rehren, 2002), and the mutual substitution of soda and potash for each other in complex systems of salt-rich silica melts, such as plant-ash based glass and faience (Tanimoto and Rehren, 2008). On the basis of archaeological faience compositions, Santopadre and Verita (2000) proposed that only one flux had been used for mixed-alkali vitreous faience based on the negative relationship between soda and potash, as well as the constant total alkali content $\left(\mathrm{Na}_{2} \mathrm{O}+\mathrm{K}_{2} \mathrm{O}\right)$.

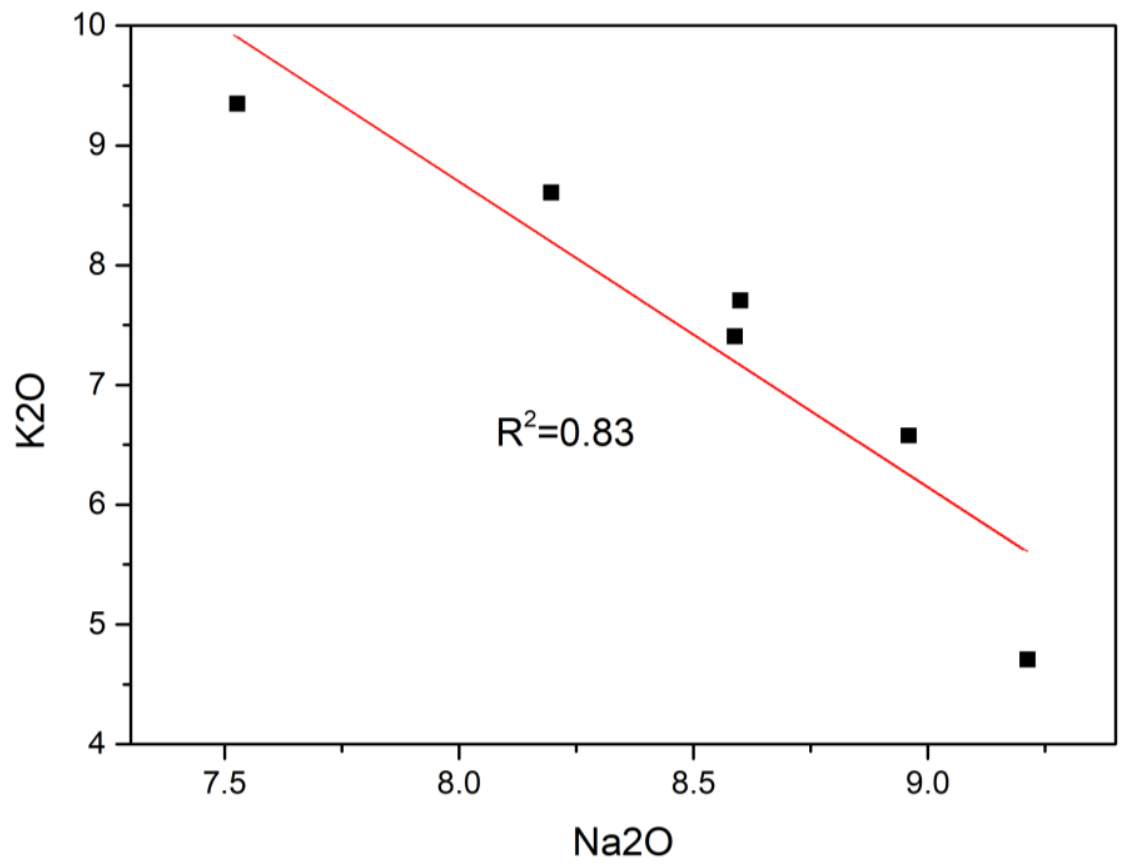

Fig 6. Scatter plot showing the concentrations of $\mathrm{K}_{2} \mathrm{O}$ and $\mathrm{Na}_{2} \mathrm{O}$ in the glass phase of Adunqiaolu faience (wt\%)

The exact source of the mixed-alkali flux is still unknown. Purified plant ash with a low content of impurities (Brill, 1992; Tite et al., 2006), impure natron (Brill, 1992), efflorescent salts from latrines or manured soils (Brill, 1992) and even cattle dung (Matin et al., 2016) could have been possible sources; however, other researchers (Sheridan et al., 2005; Shortland et al., 2007; Angelini, 2008) think that wood ash or salt-tolerant plant ash was likely to have been the source of mixed-alkali flux. These types of ashes could have been dissolved in water, leaving behind insoluble substances (lime, magnesia and phosphate) and then the soluble salts containing sodium and 
potassium could have been separated out, either as an intentional process in the preparation of the raw materials, or simply as part of the efflorescence (Rehren, 2008).

\subsection{Implications for trans-European exchange}

Apart from Europe, mixed-alkali vitreous materials are rare in Mesopotamia, Egypt and the Near East, where ancient faience is mostly soda-rich. The discovery of mixed-alkali faience beads from Adunqiaolu in Xinjiang provides additional evidence regarding the communication between East Asia and Europe throughout the Eurasian Steppe around the first half of the $2^{\text {nd }}$ millennium BC.

Well-documented materials being transferred between steppe pastoralists and urban agriculturalists in Southern-Central Asia, the Indus Valley, China, the Iranian Plateau, and perhaps even Mesopotamia in the Late Bronze Age indicate that Central Asian populations facilitated trade and resource acquisition for a variety of civilizations (Frachetti et al., 2012). Anthony (2008) emphasized the importance of trade during the urbanisation of pastoral societies by the end of the $3^{\text {rd }}$ millennium BC; for example, three bracelets presenting a similar shape to ones from Harappan sites were excavated from a tomb belonging to a female individual at Gonur Depe in Turkmenistan (Bakry, 2016). The stepped pyramid, which was a basic element in the decorative artwork of BMAC (Bactria-Margiana Archaeological Complex, a Central Asian Bronze Age culture dated to ca. 2300-1700 BC) pottery, jewellery and metalwork also appeared on Sintashta pottery in Ural-Tobol steppes and later became a standard design in Petrovka and Andronovo pottery (Anthony, 2008).

By the end of the $3^{\text {rd }}$ millennium $B C$, trade and conquest began to connect the ancient world together into an interacting system, connecting the most powerful cities in the Near East, Iran and South Asia (Anthony, 2008; Frachetti et al., 2012). All of these archaeological materials indicate the opening of the Eurasian Steppe, which made early faience exchange across large areas possible.

Similar segmented-shaped faience beads to those discussed in this paper were discovered at Tell el Amarna (1600-1300 BC) in Egypt (Tite et al., 2007) and in Harappa (2600-1900 BC) in the Indus Valley (Gu et al., 2016). Particularly in Europe, large quantities of rounded segmented faience beads were discovered in Bronze Age sites. Segmented beads made of bone as well as bronze formed part of a standardized assemblage for the North Caucasus since they first appeared in the Early Catacomb Culture (2600-2000 BC). Subsequently, the craftsmen of the Catacomb Culture in the North Caucasus region began to make such beads of faience (Shortland, 2007), and some of it is of the mixed-alkali type, similarly to Adunqiaolu faience (Shortland, 2007). Thus, the faience beads from the North Caucasus region are similar to those from the Adunqiaolu site in terms of typology and chemical composition. However, it is premature to say that there is a direct relationship between the North Caucasus region and the Adunqiaolu site based only on the faience traditions regarding design and manufacturing technology, without looking first at the key intermediate region.

In the Steppe, the earliest faience is from Sintashta. Segmented faience has also been found in Sintashta burials, dating from the early $2^{\text {nd }}$ millennium to the $16^{\text {th }}$ century BC (Виноградов, 2003). Considering that Adunqiaolu is connected with the large Andronovo complex which originally derived from the Sintashta - Petrovka 
Culture, it is logical to link Adunqiaolu faience with similar faience associated with the Sintashta Culture. The latter is arguably from the same technological tradition and provides new evidence of exchanges of material and knowledge across the Eurasian Steppe during the Bronze Age. Commodities such as metals and precious stones, and innovations in riding and transport played an important role in this expanding trade and exchange (Frachetti, 2012; Kohl, 1987). Now, faience can be added to this list.

In a recently published paper, Lin et al. (2019) presented new analytical data on mixed-alkali and soda-rich faience from the Tianshanbeilu Cemeteries in Eastern Xinjiang. The mixed-alkali segmented faience beads from tomb M200 are most likely to be dated from 1500 to 1400 BC although there is no direct date available from M200; at least roughly 150 years later than the beads analysed in this work. The weight ratio between soda and potash in the glassy phase of Tianshanbeilu faience falls also firmly into the mixed-alkali range of 0.5 to 1.5 , as defined by Vandiver (2008). Thus, the mixed-alkali composition and the segmented shape of the beads are similar in both the Adunqiaolu faience and Tianshanbeilu faience in western and eastern Xinjiang. Lin et al. (2019) pointed out that in the mid-second millennium BC, Xinjiang faience might have been imported from the North Caucasus. Thus, the presence of Adunqiaolu faience further indicates that mixed-alkali faience from Europe might have spread to eastern Xinjiang through Adunqiaolu in the mid-second millennium BC.

\section{Conclusion}

Adunqiaolu faience beads are the earliest form of faience found in China so far. Compositional analyses showed that these segmented faience beads were of the LMHK mixed-alkali type and that plant ash was possibly used as a raw material in the making of the fluxing agent. Regarding composition and shape, Adunqiaolu faience is different from early potash-rich faience found in the Yellow River basin; however, it has a strong correlation with faience from the Eurasian Steppe and Europe, thus revealing early cross-cultural exchange between the West and the East in the Old World.

This study was the first to reveal the occurrence of early faience in the region of the western Tianshan Mountains. The discovery of faience in association with the Andronovo tradition in the Adunqiaolu site strongly suggests that there could be other similar objects to be discovered in Late Bronze Age to Iron Age sites along the edge of the Eastern Steppe in West China. The examination of Adunqiaolu faience is only an initial step towards future extensive research about the objects found in the aforementioned areas. This will broaden our understanding regarding early social and cultural interaction, and exchange of information and technologies across the Eurasian Steppe.

\section{Acknowledgements}

We would like to thank Mr. Guojun Shang and Mr. Bateer of Wenquan County Cultural Heritage Administration, Bo'ertala Mongol Autonomous Prefecture, Xinjiang for their help in sample preparation. We also thank Prof. Ian Freestone of University College London, Prof. Yanxiang Li of University of Science and Technology Beijing, Prof. Qinglin Ma of Shandong University, Prof. Xiaocen Li of Nanjing University of Information Science \& Technology, and Associate Professor Jianfeng Cui of Peking 
University for their excellent support in this work. We sincerely thank Dr Miljana Radivojević of the McDonald Institute for Archaeological Research, University of Cambridge, for providing valuable references and helping to translate some Russian references into English. Comments from three anonymous reviewers helped us to strengthen our paper, and are gratefully acknowledged.

\section{References}

Angelini I., 2008. Faience production in Northern and Western Europe. In: Tite M.S. and Shortland A.J. (eds), Production technology of faience related early vitreous materials. Oxford University School of Archaeology, Oxford, pp. 129-146.

Angelini I., Artioli G., Bellintani P., Polla, A., 2005. Protohistoric vitreous materials of Italy: from early faience to Final Bronze Age glass. In: Annales du 16e Congres de I' Association Internationale pour I' Histoire du Verre, Nottingham, pp. 32-36.

Angelini I., Artioli G., Polla A., de Marinis, R.C., 2006. Early Bronze Age faience from north Italy and Slovakia: a comparative archaeometric study. In: Arantegui J.P. (ed), 34th International Symposium on Archaeometry, pp. 371-378.

Anthony D.W., 2008. The Horse, the Wheel and Language: How Bronze-Age Riders from the Eurasian Steppes Shaped the Modern World. University Press, Princeton.

Bakry A., 2016. Prehistoric Contacts between Central Asia and India. In: Dubova N.A., Antonova E.V., Kozhin P.M., (eds), Transactions of Margiana Archaeological Expedition. Moscow, pp. 422-435.

Виноградов Н.Б., 2003. Могильник бронзового века. Кривое Озеро в Южном Зауралье. Южно-ральское книжное издательство, Челябинск, рр. 239-240 (in Russian).

Bouquillon A., Kaczmarczyk A., Vandiver P. B., 2008. Faience production in the Near East and the Indus Valley. In: Tite M.S. and Shortland A.J. (eds), Production technology of faience related early vitreous materials. Oxford University School of Archaeology, Oxford, pp. 93-109.

Brill R.H., 1992. Chemical analyses of some glasses from Frattesina. J. Glass Stud. 34, 11-22.

Brill R.H., Tong S., Zhang F., 1989. The chemical composition of a faience bead. J. Glass Stud. 31, 11-15.

Cong D. X., Jia Xiaobing, Guo Wu, et al., 2013. The Aduun Chuluu Site and Cemetery in Wenquan County, Xinjiang. Kaogu (Archaeology) 7, 25-32 (in Chinese).

Cong D. X., Jia W., Betts A., et al., 2017. Adonqolo: New Type of Bronze Age Remains in the Western Tianshan Mountains. Xi Yu Yan Jiu (The Western Regions Stud.) 4, 15-28 (in Chinese).

Conte S., Matarese I., Vezzalini G., et al., 2019. How much is known about glassy materials in Bronze and Iron Age Italy? New data and general overview. Archaeol. and Anthropol. Sci. 11, 1813-1841.

Dong J. Q., Gan F. X., Xia X. W., Li Q. H., Liu S., Gu D. H., 2016. Scientific research on the earliest Chinese glazed pottery. In: Gan F. X., li Q. H. and Henderson (eds), Recent advances in the scientific research on ancient glass and glaze, World 
century; World Scientific, pp 303-319.

Frachetti M.D, Anthony D.W., Epimakhov A.V., et al., 2012. Multiregional Emergence of Mobile Pastoralism and Nonuniform Institutional Complexity across Eurasia. Current Anthropol. 53, 2-38.

Gan F. X., 2016. The chemical composition development and technological origination of Chinese ancient glass in Huang River and Changjiang River. In: Gan F. X., et al. (eds), The Technological development of Ancient Glass in China. Shanghai Scientific \& Technical Publishers, Shanghai, pp 271-282 (in Chinese).

Gratuze B., Janssens K., 1993. Provenance analysis of glass artefacts. In: Comprehensive Analytical Chemistry. Elsevier, pp. 663-712.

Gratuze B., Louboutin C., Billaud Y., 1998. Les perles protohistoriques en verre du Musées des Antiquités nationales. Antiquités Nation. 30, 11-24.

Gu Z., Kenoyer J. M., Yang Y., 2016. Investigation of ancient Harappan faience through LA-ICP-AES and SR- $\mu$ CT. J. Instrum. 11(4: C04001), 1-9.

Henderson J., 1988. Electron Probe Microanalysis of Mixed-alkali glasses. Archaeom. 30, 77-91.

Henderson J., 1993. Chemical analysis of the glass and faience from HauteriveChampreveyeres. In: Rychner-Farragi A.M. (ed), Metal et parure au Bronze final, Hauterive-Champreveyres 9, Switzerland, pp. 111-116.

Henderson, J. 2013. Ancient Glass, an interdisciplinary exploration. New York and Cambridge: Cambridge University Press.

Jia P. W., Betts A., Cong D., et al., 2017. Adunqiaolu: new evidence for the Andronovo in Xinjiang, China. Antiq. 91, 621-639.

Kaczmarczyk A., Vandiver P. B., 2008. Faience production in Egypt. In: Tite, M.S. and Shortland A.J. (eds), Production technology of faience and related early vitreous materials. Oxford University School of Archaeology, Oxford, pp. 66-72.

Kohl P.L., 1987. The Use and Abuse of World Systems Theory: The Case of the Pristine West Asian State. Advances in Archaeological Method \& Theory 11, 1-35.

Lei Y., Xia Y., 2016. Study on production techniques and provenance of faience beads excavated in China. J. Archaeol. Sci. 52, 32-42.

Li Q.H., Dong J.Q., Gan F.X., 2009. Research and Discussion on Chemical Composition and Technics of the early Faience and Glass Artifacts Unearthed from China. J. Guangxi Univ. for National. (Natural Science Edition) 4, 31-41 (in Chinese).

Lin Y.X., Rehren Th., Wang H., et al., 2019. The beginning of faience in China: A review and new evidence. J. Archaeol. Sci. 105, 97-115.

Liu N., Yang Y.M., Wang Y., et al. 2017. Nondestructive characterization of ancient faience beads unearthed from Ya'er cemetery in Xinjiang, Early Iron Age China. Ceram. Int. 43, 10460-10467.

Matin M., Matin M., 2016. Egyptian faience glazing by the cementation method part 2: cattle dung ash as a possible source of alkali flux. Archaeol. and Anthropol. Sci. $8,125-134$.

Nikita, K. and Henderson, J.,2006 Glass analyses from Mycenaean Thebes and Elateia: compositional evidence for a Mycenaean glass industry, J. Glass Studies 48, 71120. 
Nikita K., Nightingale G., Chenery S., 2017. Mixed-alkali glass beads from ElateiaAlonaki: tracing the routes of an alien glass technology in the periphery of postpalatial Mycenaean Greece. In: Fotiadis M., Laffineur R., Lolos Y. (eds), HesperosThe Aegean Seen from the West. Proceedings of the 16th International Aegean Conference, pp. 515-524.

Rehren Th., 2000. Rationales in Old World base glass compositions. J. Archaeol. Sci. 27, 1225-1234.

Rehren Th., 2008. A review of factors affecting the composition of early Egyptian glasses and faience: alkali and alkali earth oxides. J. Archaeol. Sci. 35, 1345-1354.

Robinson C., Baczyńska B., Polańska M., et al. 2004. Origins of Faience in Poland. Sprawozdania Archeol. 56, 79-154.

Santopadre P., Verita A.M., 2000. Analyses of the production technologies of Italian vitreous materials of the Bronze Age. J. Glass Stud. 42, 25-40.

Sheridan A., Shortland A., 2004. Faience in Early Bronze Age Britain and Ireland. In: Scotland in ancient Europe: the Neolithic and Early Bronze Age of Scotland in their European context. Society of Antiquaries of Scotland, Edinburgh, pp 263279.

Sheridan A., Eremin K., Shortland A., 2005. Understanding Bronze Age faience in Britain and Ireland. In: Materials Research Society Symposium Proceedings Volume 852, pp. 217-229.

Shortland A., Shishlina N., Egorkov A., 2007. Origin and Production of Faience beads in the North Caucasus and the Northwest Caspian Sea Region in the Bronze Age. In: Lyonnet B. (ed), Les cultures du Caucase: leurs relations avec le Proche-Orient, pp. 269-283.

Shugar A., Rehren Th., 2002. Formation and composition of glass as a function of firing temperature. In: Glass Technol. 43C (Proc. XIX Int. Congr. Glass), pp. 145-150.

Tanimoto S., Rehren Th., 1992. Interactions between silicate and salt melts in LBA glassmaking. J. Archaeol. Sci. 35, 2566-2573.

Tite M.S., Freestone I.C., Bimson M., 1983. Egyptian faience: an investigation of the methods of production. Archaeom. 25(1), 17-27.

Tite M.S., Shortland A.J., Maniatis Y., et al. 2006. The composition of the soda-rich and mixed alkali plant ashes used in the production of glass. J. Archaeol. Sci. 33, 1284-1292.

Tite M.S., Manti P., Shortland A. J., 2007. A technological study of ancient faience from Egypt. J. Archaeol. Sci. 34, 1568-1583.

Tite M.S., Shortland J., 2008. Production technology of faience and related early vitreous materials. Oxford University School of Archaeology, Oxford, pp 17.

Vandiver P. B., 1983. Egyptian faience technology, Appendix A. In: Kaczmarczyk A., Hedges R.E.M., (eds), Ancient Egyptian Faience: An Analytical Survey of Egyptian from Predynastic to Roman Times. Aris and Phillips, Warminster, pp A1-114.

Vandiver P. B., 1998. A review and proposal of new criteria for production technologies of Egyptian faience. In: Colinart S., Menu M., (Eds), La Couleur dans le Peinture et l'Emaillage de 'Egypte Ancienne. Edipuglia, Bari, pp 121-139.

Vandiver P. B., 2008. Raw materials and fabrication methods used in the production 

of faience. In: Tite M.S. and Shortland A.J. (eds), Production technology of faience related early vitreous materials. Oxford University School of Archaeology, Oxford, pp. 37-55.

Venclová, N., Hulínský, V., Henderson, J., Chenery, S., Šulová, L. and Hložek, J., 2011. Late Bronze Age mixed-alkali glasses from Bohemia. Archeologické rozhledy, 63, 559-585.

Wang Y.Z., 2019. The Technological Research of Faience in Western-Zhou and EasternZhou Periods. University of Science and Technology Beijing (in Chinese). 


\begin{tabular}{|c|c|c|c|c|c|c|c|c|c|c|c|c|c|c|c|c|}
\hline $\begin{array}{c}\text { Sample } \\
\text { no. }\end{array}$ & Test area & $\mathrm{Na}_{2} \mathrm{O}$ & $\mathrm{K}_{2} \mathrm{O}$ & $\mathrm{TiO}_{2}$ & MgO & $\mathrm{SiO}_{2}$ & $\mathrm{Fe}_{2} \mathrm{O}_{3}$ & $\mathrm{Al}_{2} \mathrm{O}_{3}$ & $\mathrm{Cl}$ & CuO & $\mathrm{CaO}$ & $\mathrm{SnO}_{2}$ & $\mathrm{PbO}$ & $\mathrm{P}_{2} \mathrm{O}_{5}$ & $\mathrm{Na}_{2} \mathrm{O} / \mathrm{K}_{2} \mathrm{O}$ & $\begin{array}{c}\text { Unnormalized } \\
\text { total }\end{array}$ \\
\hline \multirow[t]{2}{*}{ ADQL001 } & IAL-mean & 9.06 & 7.00 & NA & 0.50 & 67.9 & 0.59 & 1.59 & 1.28 & 9.90 & 1.93 & NA & NA & 0.20 & 1.30 & 100.57 \\
\hline & BDY-mean & 8.14 & 8.41 & 0.10 & 0.53 & 67.3 & 0.72 & 1.80 & 1.24 & 8.86 & 2.30 & 0.31 & NA & 0.27 & 1.00 & 99.75 \\
\hline \multirow[t]{2}{*}{ ADQL002 } & IAL-mean & 7.52 & 9.37 & 0.11 & 0.18 & 70.4 & 1.16 & 1.82 & 0.88 & 7.81 & 0.55 & NA & NA & 0.15 & 0.80 & 98.43 \\
\hline & BDY-mean & 7.53 & 9.32 & NA & 0.56 & 72.0 & 0.52 & 2.37 & 0.81 & 5.17 & 1.45 & NA & NA & 0.20 & 0.80 & 97.18 \\
\hline \multirow[t]{2}{*}{ ADQL003 } & IAL-mean & 8.92 & 6.68 & NA & 0.23 & 70.5 & 0.37 & 2.09 & 1.02 & 8.95 & 0.83 & NA & NA & 0.29 & 1.30 & 98.15 \\
\hline & BDY-mean & 9.00 & 6.47 & NA & 0.22 & 71.8 & 0.38 & 2.04 & 0.41 & 8.42 & 0.84 & NA & NA & 0.38 & 1.40 & 97.58 \\
\hline \multirow[t]{2}{*}{ ADQL004 } & IAL-mean & 9.76 & 4.76 & NA & 0.62 & 69.8 & 0.60 & 1.81 & 1.30 & 6.70 & 4.28 & NA & NA & 0.23 & 2.10 & 99.79 \\
\hline & BDY-mean & 8.66 & 4.66 & NA & 0.57 & 73.3 & 0.71 & 2.66 & 1.24 & 4.75 & 3.13 & NA & NA & 0.21 & 1.90 & 99.03 \\
\hline \multirow[t]{2}{*}{ ADQL005 } & IAL-mean & 7.75 & 8.61 & 0.30 & 0.27 & 70.5 & 1.76 & 1.88 & 0.91 & 7.27 & 0.59 & NA & NA & 0.19 & 0.90 & 99.78 \\
\hline & BDY-mean & 8.64 & 8.60 & NA & 0.29 & 70.3 & 0.38 & 2.52 & 1.00 & 7.28 & 0.66 & NA & NA & 0.22 & 1.00 & 98.28 \\
\hline \multirow[t]{2}{*}{ ADQL006 } & IAL-mean & 9.14 & 6.30 & NA & 0.42 & 70.0 & 0.67 & 1.74 & 1.29 & 8.03 & 2.13 & NA & NA & 0.25 & 1.50 & 98.93 \\
\hline & BDY-mean & 8.04 & 8.51 & 0.10 & 0.64 & 68.2 & 1.47 & 2.41 & 1.05 & 7.44 & 1.83 & NA & NA & 0.27 & 0.90 & 97.31 \\
\hline \multicolumn{2}{|c|}{ Corning glass B } & $\mathrm{Na}_{2} \mathrm{O}$ & $\mathrm{K}_{2} \mathrm{O}$ & $\mathrm{TiO}_{2}$ & MgO & $\mathrm{SiO}_{2}$ & $\mathrm{Fe}_{2} \mathrm{O}_{3}$ & $\mathrm{Al}_{2} \mathrm{O}_{3}$ & $\mathrm{Cl}$ & $\mathrm{CuO}$ & $\mathrm{CaO}$ & $\mathrm{SnO}_{2}$ & $\mathrm{PbO}$ & $\mathrm{P}_{2} \mathrm{O}_{5}$ & & Sum \\
\hline \multicolumn{2}{|c|}{ Test-1 } & 16.41 & 1.04 & 0.14 & 1.06 & 61.3 & 0.32 & 4.18 & 0.18 & 3.03 & 8.82 & NA & NA & NA & & 96.51 \\
\hline \multicolumn{2}{|c|}{ Test-2 } & 16.48 & 0.98 & 0.11 & 1.07 & 59.9 & 0.32 & 4.19 & 0.17 & 2.98 & 8.66 & NA & NA & 0.87 & & 95.71 \\
\hline \multicolumn{2}{|c|}{ Test-3 } & 16.03 & 0.99 & 0.12 & 1.06 & 61.2 & 0.33 & 4.27 & 0.20 & 3.04 & 8.75 & NA & 0.48 & 0.85 & & 97.36 \\
\hline \multicolumn{2}{|c|}{ Reference content wt\% } & 17.00 & 1.00 & 0.09 & 1.03 & 61.6 & 0.34 & 4.36 & 0.20 & 2.66 & 8.56 & 0.04 & 0.61 & 0.82 & & 97.36 \\
\hline
\end{tabular}

